\title{
Gaya Komunikasi Politik Twitter Partai Gerindra
}

\author{
Ayu Nenden Assyfa Putri ${ }^{1 *}$ \\ ${ }^{1}$ Pascasarjana Manajemen Komunikasi, Fakultas Ilmu Sosial dan Ilmu Politik, Universitas Indonesia \\ J1. Margonda Raya, Pondok Cina, Kecamatan Beji, Kota Depok, Jawa Barat \\ E-mail: ${ }^{1}$ ayu.nenden01@ui.ac.id
}

Received: June 2021; Accepted: October 2021; Published: December 2021

\begin{abstract}
Social media, especially Twitter, as one of the most widely used platforms on the internet, is now being used by political organizations to convey their political communication messages. This study uses a descriptive qualitative method by analyzing the communication style conveyed by the Gerindra party Twitter account to its followers. In looking for references, researchers use a systematic review method wherein the authors must describe the search to be used, determine where and when they should search, and what terms they should use. The results of this study indicate that the style of political communication conveyed by the Gerindra Twitter account has the aim of being accepted by Twitter users, whose users are young people. Unlike the political communication messages conveyed during the 2014 \& 2019 elections, the Gerindra Twitter account conveys its political communication style in a relaxed and informative way. The relevance of the information diffusion theory in this study is when the Gerindra party takes advantage of the great opportunity of Twitter as a social media to communicate its political campaigns so that new voters can accept it in the future.
\end{abstract}

Keyword : Political Communications, Social Media, Gerindra, Diffusion Innovation Theory

\begin{abstract}
Abstrak (Times New Roman, 11 pt Bold) (300 kata)
Media sosial khususnya twitter sebagai salah satu platform yang paling banyak digunakan di internet kini dimanfaatkan organisasi politik untuk menyampaikan pesan komunikasi politiknya. Penelitian ini menggunakan metode kualitatif deskriptif dengan menganalisis gaya komunikasi yang disampaikan oleh akun twitter partai gerindra kepada followersnya. Dalam mencari referensi peneliti menggunakan metode systematic review dimana dalam kajian ini penulis harus menguraikan pencarian yang akan digunakan, menentukan dimana dan kapan mereka harus melakukan pencarian dan istilah apa yang harus mereka gunakan. Hasil dari penelitian ini menunjukan bahwa gaya komunikasi politik yang disampaikan oleh akun twitter gerindra memiliki tujuan untuk diterima oleh pengguna twitter, yang dominasi penggunanya merupakan anak muda. Berbeda dari pesan komunikasi politik yang disampaikan pada masa pemilu 2014 \& 2019, kini akun twitter gerindra menyampaikan gaya komunikasi politiknya dengan cara santai dan informatif. Penerapan Teori Difusi Informasi pada partai gerindra terlihat ketika adanya penggunaan media twitter sebagai platform komunikasi partai dengan para audiensnya. Selain itu partai gerindra mengubah gaya komunikasi mereka dengan gaya yang lebih santai agar bisa terkait dengan generasi muda yang menggunakan twitter. Keterkaitan teori difusi informasi dalam penelitian ini adalah ketika partai gerindra memanfaatkan peluang besar dari twitter sebagai media sosial untuk mengkomunikasikan kampanye politiknya agar bisa diterima oleh pemilih baru dimasa yang akan datang.
\end{abstract}

Kata Kunci: Komunikasi Politik, Sosial Media Twitter, Partai Gerindra, Teori Difusi Informasi

doi: https://doi.org/10.51544/jlmk.v5i2.2161

(C) 2021 Jurnal Lensa Mutiara Komunikasi. This is an open access article under the CC BY-SA license Website: http://e-journal.sari-mutiara.ac.id/index.php/JLMI

http://e-journal.sari-mutiara.ac.id 


\section{PENDAHULUAN}

Hadirnya media sosial yang digunakan sebagai platform untuk melakukan pertukaran sosial memberikan medan baru bagi para politisi dan dapat menginvestasi waktu serta dapat menghemat biaya. Pejabat publik telah bertransformasi ke dalam dunia digital dengan tujuan untuk mencapai konstituen mereka. Namun pada kenyataannya media sosial dibangun tidak selalu sesuai dengan yang politisi harapkan. Mereka sebagian tidak siap untuk melakukan ketegangan demo, memelihara demokrasi yang sehat dsb.

Media sosial sebagai hal yang sangat menarik di internet kini digunakan banyak politisi sebagai media kampanye politik. Media sosial berkembang sangat signifikan dan menarik banyak perhatian dari pengguna online. Saat ini media sosial digunakan untuk komunikasi pribadi, pendidikan, promosi, berbagi informasi dan sebagainya. Selama lebih dari satu dekade, media sosial digunakan organisasi politik/politisi sebagai ajang penyampaian pesan kepada pemilihnya. Pesannya bisa berbentuk interpersonal namun sebenarnya mereka memiliki tujuan untuk menguatkan publisitas terhadap pesan politik yang telah dibuat (Abdillah, 2020:1).

Soebiraj (2020:2) menjelaskan bahwa media sosial memiliki kemampuan untuk mempromosikan citra partai politik dengan sangat mudah. Setiap partai politik menyediakan media sosial untuk berinteraksi langsung dengan audiens mereka. Hasil survey yang dilakukan oleh Social Bakers menunjukan bahwa para politisi dan organisasi politiknya memiliki minat yang tinggi untuk berinteraksi dalam media sosial. Platform media sosial memberikan ruang untuk para politisi mengakses jutaan pengguna dan menawarkan kapasitas untuk membangun rasa persahabatan dan koneksi dengan konstituen yang luas (Crawford, 2009:527 ).

Situs media sosial micro-blogging yang sangat ramai digunakan masyarakat untuk berkomunikasi adalah twitter. Media ini sangat populer digunakan para politisi untuk mengutarakan komunikasi politik serta mendengarkan suara masyarakat. Philip Cohen (dalam Sobieraj, 2020:8) menjelaskan bahwa penggunaan media sosial oleh para aktor politik untuk berinteraksi langsung dengan masyarakat memiliki manfaat yang sangat besar, karena bisa berkomunikas langsung kepada khalayak, gratis dan tanpa perlu ada mediasi dari media lain. Hal ini berpotensi untuk memberikan peluang demokrasi untuk akar rumput.

Akun resmi partai yang sangat fenomenal akhir-akhir ini adalah akun twitter Partai Gerindra. Tren penggunaan media sosial terutama twitter bagi organisasi partai politik dilakukan oleh Partai Gerindra sehingga sampai saat ini (25/06/2021) twitter tersebut memiliki pengikut sebanyak 588,3 ribu. Akun tersebut sempat beberapa kali menjadi perbincangan warga twitter karena membalas tweet followersnya dengan bahasa gaul ala anak muda di twitter. Kenapa menjadi perbincangan? Karena yang kita ketahui sebelumnya akun twitter partai selalu saja mengkomunikasikan pesan partai dengan bahasa kaku dan baku.

Organisasi politik menggunakan media sosial untuk melakukan penyampaian pesan politik kepada masyarakat. Alasan utama penggunaan media sosial sebagai platform komunikasi para politisi karena media tersebut gratis dan bisa menjangkau pesan secara luas di seluruh kelas sosial ekonomi. Selain itu media sosial dapat menjangkau berbagai kalangan termasuk para pemilih muda untuk berpartisipasi lebih besar (Joseph, 2012:33).

Artikel ini bertujuan untuk menganalisis perubahan yang diambil dari akun twitter Partai Gerindra, peneliti mengaitkan dengan perspektif teori difusi inovasi dimana asumsi teori ini menjelaskan bahwa twitter sebagai media massa sangat berpengaruh terhadap pembaharuan dan segala inovasi yang berkembang dalam lingkungan masyarakat. 


\section{TINJAUAN LITERATUR}

Sosial Media

Media sosial adalah istilah yang sering digunakan untuk merujuk pada penggunaan media baru yang melibatkan berbagai perspektif dan partisipasi yang sangat interaktif. Perkembangan media dibagi menjadi dua zaman yang berbeda, yakni zaman siaran dan zaman interaktif. Di zaman penyiaran media secara eksklusif terpusat pada satu entitas, seperti televisi, radio dan surat kabar yang bisa menyalurkan informasinya kepada banyak orang. Pada zaman siaran umpan balik dari audiens tidak dapat secara langsung diterima, tertunda dan bersifat impersonal. Dengan hadirnya media digital, interaksi dapat dilakukan dengan mudah. Dengan hadirnya media sosial individu dapat memiliki kemampuan untuk mencari informasi dari beberapa sumber dan dapat berdialog dengan audiens lainnya melalui suatu platform. Selain itu karakteristik yang dimiliki media sosial antara lain bisa melibatkan bentuk partisipasi dari masyarkat. Sejalan dengan sifatnya yang partisipatif, media sosial melibatkan interaksi antara berbagai masyarakat yang saling terhubung melalui suatu media (Manning, 2014:1158).

Selain berfungsi sebagai saluran komunikasi, media sosial pada hakikatnya digunakan dalam du acara utama. Pertama, digunakan sebagai media komunikasi dengan pihak eksternal, seperti pelanggan, vendor sampai masyarakat luas. Suatu organisasi yang menggunakan media sosial untuk menyampaikan komunikasinya memiliki strategi multi cabang yang melintasi berbagai macam platform. Kedua, media sosial digunakan untuk komunikasi internal suatu organisasi (Leonardi, 2019:2).

\section{Komunikasi Politik}

Grishin (2012:4) menjelaskan bahwa komunikasi politik adalah suatu sistem yang memproduksi, mendistribusikan, memproses, menyimpan dan menukar informasi yang tujuannya adalah untuk mempengaruhi para audiens politik. Selain itu dalam komunikasi politik terdapat adanya pertukaran simbol dan pesan antara aktor politik, organisasi politik dan publik. Komunikasi politik adalah proses dimana kepemimpinan suatu negara, media dan warga negara saling bertukar pikiran dan memberikan makna yang berkaitan dengan pelaksanaan kebijakan publik.

Selain itu Arifin (2011:65) dalam komunikasi politik terdapat bentuk-bentuk yang dapat di elaborasikan. Pertama, Retorika atau seni bicara. Kedua, menggerakan masyarakat untuk turut serta dalam Gerakan politik. Baik itu secara lisan maupun tulisan. Ketiga, adanya propaganda yang dilakukan oleh partai politik yang memiliki tujuan untuk memberikan saran kepada publik dan menciptakan suasana menjadi tidak tenang. Keempat, adanya hubungan antar masyarakat dan politisi yang dibangun secara dua arah. Kelima, adanya bentuk komunikasi politik yang dilakukan oleh seseorang atau sekelompok orang untuk memperoleh dan memperkuat dukungan politik dari masyarakat atau pemilih. Keenam, adanya lobi politik. Ketujuh, adanya media massa yang bisa dijadikan media untuk menciptakan komunikasi yang efektif.

Komunikasi politik sebagai sistem terdiri dari sembilan elemen, yaitu aktor politik, audiens, investigasi audiens, organisasi yang menciptakan konten komunikasi politik, organisasi yang menyebarkan konten komunikasi politik, organisasi yang memastikan penyebaran konten komunikasi politik, organisasi yang mengendalikan proses komunikasi politik dan organisasi yang menyediakan penyimpanan informasi politik Grishin (2012:5).

Teori Difusi Inovasi 
Rogers (1962) yang mengembangkan model pertama difusi inovasi menjelaskan difusi inovasi sebagai proses dimana suatu inovasi dikomunikasikan dalam saluran tertentu melalui suatu sistem sosial. Proses difusi terdiri dari empat elemen kunci : inovasi, sistem sosial yang dipengaruhi oleh inovasi, saluran komunikasi dan waktu (Chang, 2010:2). Sedangkan Dearing (2018:183) menjelaskan difusi adalah proses sosial yang terjadi kepada orang dalam menghadapi inovasi yang tujuannya adalah meningkatkan wawasan. Dalam klasifikasinya, difusi melibatkan suatu inovasi yang dikomunikasikan melalui saluran tertentu dari waktu ke waktu di dalam suatu platform sosial. Teori Difusi Inovasi menawarkan wawasan tentang pertanyaan terkait dengan alasan penggunaan teknologi baru dan sejauh mana dampaknya. Difusi juga dijelaskan sebagai proses dimana suatu inovasi dapat diadopsi dan diterima oleh anggota masyarakat.

Teori difusi inovasi memberikan penjelasan yang sistematis mengenai suatu informasi yang tujuannya untuk dikomunikasikan melalui berbagai saluran dalam suatu sistem sosial. Inovasi dapat berupa suatu ide, praktik atau objek yang dianggap baru oleh individu. Melalui teori difusi inovasi, media sosial dianggap sebagai saluran baru untuk menyebarkan suatu informasi atau berita (Ma, 2013:600). Folorunso dkk (2009:362) menjelaskan bahwa faktor utama yang dapat mempengaruhi proses difusi inovasi sendiri adalah tentang bagaimana informasi tentang inovasi tersebut dikomunikasikan serta waktu, sifat sosial dapat diperkenalkan. Sosial media dianggap sebagai suatu inovasi yang hebat, oleh karena itu difusi dan peningkatan penggunaan sosial media dapat dikaitkan dengan masing-masing keputusan suatu organisasi untuk berinovasi. Sebagai salah satu teori komunikasi yang paling berpengaruh dalam komunikasi pemasaran, fokus dari teori difusi inovasi adalah tentang cara suatu informasi disebarluaskan.

\section{METODE PENELITIAN}

Penelitian ini menggunakan pendekatan metode kualitatif. Metode kualitatif menurut Creswell (2009, hlm. 38) adalah suatu proses penelitian dari pemahaman yang berdasarkan pada metodologi yang menyelidiki suatu fenomena sosial dan masalah manusia. Peneliti membuat suatu gambaran kompleks dan mendalam mengenai tanggapan responden dan melakukan studi pada kasus yang dilakukan. Metode kualitatif adalah cara efektif untuk bisa mendapatkan hasil yang mendalam (Daymond, dkk, 2011, hlm. 7). Menurut Kirk \& Miller (dalam Creswell, 2009, hlm. 252) menjelaskan bahwa paradigma penelitian kualitatif pada hakikatnya berasal dari antropologi kultural dan sosiologi di Amerika. Tujuan penelitian kualitatif adalah untuk memahami situasi, peristiwa, kelompok atau interaksi sosial tertentu. Penelitian kualitatif menjadikan peneliti memasuki dunia informan melalui interaksi berkelanjutan karena mencari makna-makna dan perspektif informan.

Dalam mencari referensi peneliti menggunakan metode systematic review dimana Dempster (dalam Hanley, 2013:4) menjelaskan bahwa systematic review merupakan sebuah kajian literatur yang komprehensif dan berbeda dari tinjauan literatur tradisional karena dilakukan dengan langkah yang sistematis. Tujuan dari systematic review adalah mengurangi bias dan dapat mensintesis informasi yang akan diperoleh. Latar belakang dari systematic review berisi ringkasan singkat tinjauan pustaka, pertanyaan penelitian dan tujuan penelitian. Dalam melaksanakan kajian systematic review diperlukan dua hal yakni diskusi literatur mengenai objek yang akan diteliti dan pertanyaan penelitian yang sudah jelas dipertimbangkan. Penulis dalam kajian ini harus menguraikan pencarian yang akan digunakan, menentukan dimana dan kapan mereka harus melakukan pencarian dan istilah apa yang harus mereka gunakan. Kelayakan sumber juga harus menjadi acuan, apakah kutipan yang akan ditulis relavan dengan 
penelitian atau tidak. Langkah selanjutnya penulis akan melakukan ekstraksi data: data yang mereka ekstrak dari kutipan dan bagaimana langkahnya. Selain itu peneliti melakukan analisis terhadap akun twitter gerindra untuk melihat gaya komunikasi politik yang disampaikan kepada para pengikutnya.

Selain itu dalam menemukan suatu isu peneliti menggunakan teknik analisa konten. Menurut Krippendorf (2009:13), teknik analisa konten merupakan suatu bagian dari penelitian dimana seorang peneliti mengambil suatu teks atau konten dari suatu media. Analisa konten sendiri merupakan teknik dimana peneliti menyimpulkan suatu makna dari suatu teks yang sudah melewati tahap-tahap yang dapat dipercaya, dapat diaplikasikan ke dalam beberapa konteks dan kredibel.

\section{HASIL DAN PEMBAHASAN}

Pada umumnya akun resmi suatu organisasi partai seringkali bersifat formal. Konten di dalamnya hanya menjelaskan agenda-agenda partai yang sifatnya tidak informatif terutama kepada pengguna twitter muda di Indonesia. Pada masa pemilihan presiden tahun 2019 akun partai gerindra sudah sangat aktif untuk mengkampanyekan calonnya kepada masyarakat twitter. Gaya komunikasi yang disampaikan pada saat itu masih bersifat formal dan seringkali menjadi bahan hujatan karena informasi yang disampaikan terlalu berlebihan.

Yang lalu biarlah berlalu, berbeda dari tahun 2019, kini akun twitter gerindra memiliki gaya komunikasi politik yang berbeda, konten atau tweet yang disampaikan kepada audiens tentu masih bersifat informatif untuk melakukan branding terhadap partainya, namun komunikasi yang dikemas kini sangat santai dan menyesuaikan anak-anak twitter.

Mulyadi (2021) dalam artikelnya yang dimuat dalam media mojok.com melihat pandangan yang sama terkait komunikasi politik yang disampaikan oleh akun twitter partai gerindra. Menjadi admin dalam media sosial bukanlah hal yang mudah karena harus mengetahui secara detail pesan brand yang akan disampaikan (Product Knowledge) dan yang paling utama adalah harus bisa menyesuaikan karakteristik followersnya. Untuk media sosial twitter, admin dituntut harus aktif dan interaktif karena aktifitas komunikasi mereka akan muncul kedalam beranda para followers. Twitter sebagai media sosial memiliki potensi yang sangat potensial dengan dibuktikan aktifnya admin membalas komentar followersnya.

Sangat terkait dengan pernyataan diatas, akun twitter partai gerindra (@Gerindra) yang citranya tidak terlalu memiliki kesan muda kini perlahan sudah mulai membangun untuk mengubah gaya komunikasi yang santai dan asik kepada followers twitternya sehingga sangat menjadi sorotan bagi kaum milenial dan gen z. Admin twitter Gerindra berkali-kali membuat tweet dengan membahas konten yang sangat terkait dengan fenomena yang disukai anak muda saat ini. Sehingga tidak memerlukan waktu lama peningkatan followers dari akun tersebut naik drastis. Berikut adalah contoh cuitan akun twitter gerindra dalam membalas salah satu followersnya : 


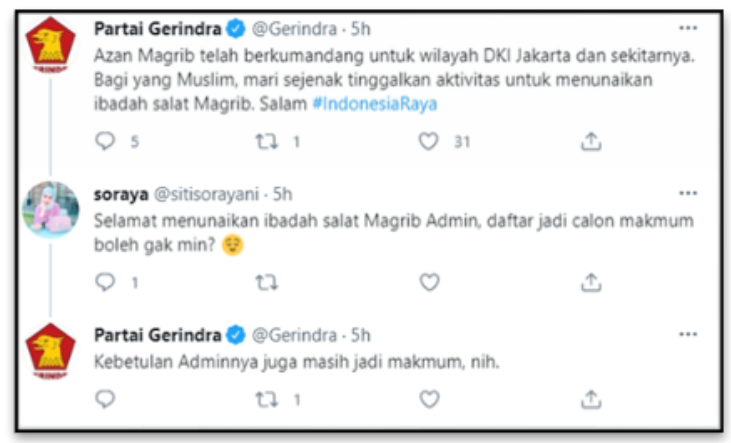

Gambar I. Tweet akun twitter @Gerindra

Selain itu gaya komunikasi yang disampaikan oleh akun twitter gerindra yang sempat menghebohkan warganet adalah adanya balasan santai yang dilakukan oleh admin. Akun twitter @ ykzr mengunggah sebuah foto yang menyebutkan bahwa Ketua Umum Partai Gerindra yakni Bapak Prabowo Subiarto wajahnya mirip dengan bayi yang ada di dalam produk perawatan bayi.

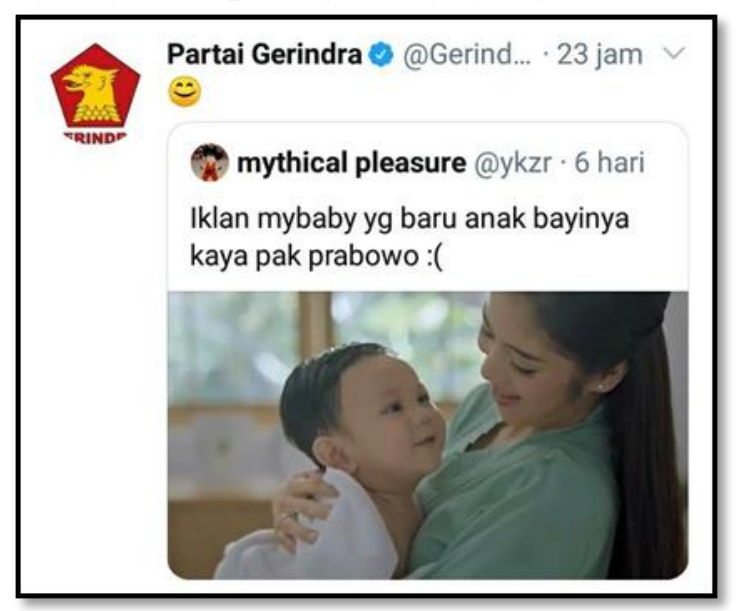

Gambar 2. Tweet akun twitter @ Gerindra

Dengan gaya komunikasi yang disampaikan oleh admin twitter partai gerindra, masih banyak warganet yang bertanya-tanya mengapa akun tersebut kini menyampaikan komunikasi yang sangat mudah diterima oleh masyarakat dibandingkan dengan cuitan twitter saat pemilu 2019 lalu. Admin gerindra menjelaskan bahwa tujuan cuitan tersebut yakni untuk mengurangi dampak negatif terhadap partai gerindra pasca pemilu 2014 \& 2019. Dimana pada masa itu terdapat kubu A dan kubu B yang sangat mempengaruhi keharmonisan kehidupan bermasyarakat. Selain itu admin gerindra menjelaskan walaupun pandangan politik berbedabeda, yang penting isi konten yang disampaikan kepada masyarakat di twitter bisa tetap "receh" dan informatif.

Terlepas dengan gaya santai yang saat ini dibuat oleh akun twitter gerindra kepada masyarakat. Komunikasi politik masih selalu disampaikan kepada masyarakat, seringkali menginformasikan terkait dengan agenda-agenda partai, diskusi dengan masyarakat terkait isu negara, informasi partai dan sebagainya. 


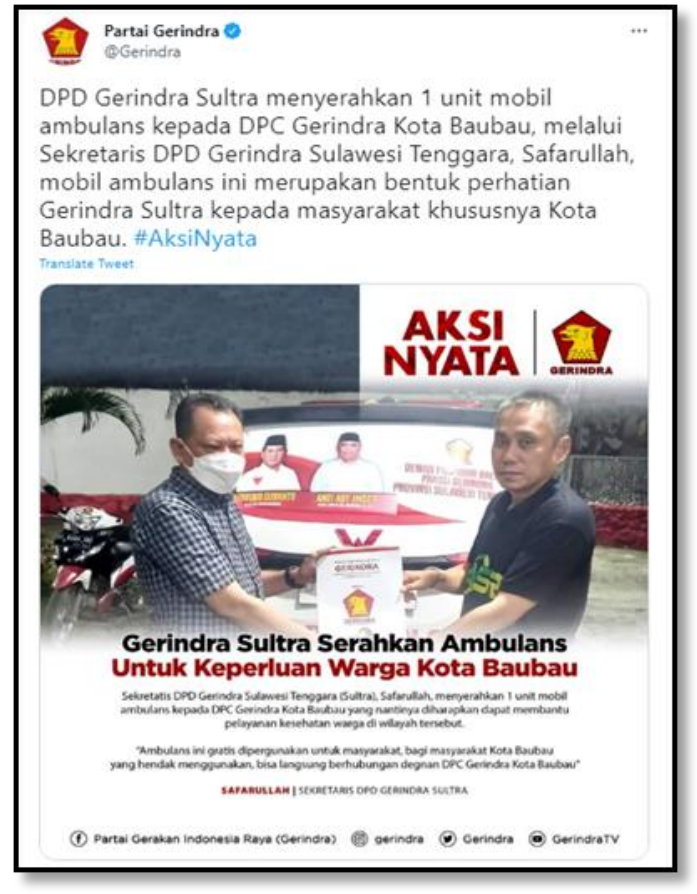

Gambar 3. Tweet akun twitter @Gerindra

Media sosial merupakan wadah yang tidak formal dan bersifat dua arah, tanpa adanya mediator sehingga bisa mengakibatkan pengguna berbicara lebih diluar batas. Kreis dalam (Sobieraj, dkk, 2020:2) menjelaskan bahwa peran sosial media adalah sebagai alat publisitas karena para politisi menggunakannya dengan bertujuan untuk menyebarkan keyakinan politik dan sikap terhadap kebijakan yang ada. Penggunaan media sosial yang dilakukan oleh politisi adalah suatu tindakan yang dilakukan secara strategis dan disengaja. Mereka menjangkau khalayak luas bahkan diluar konstituen mereka sendiri untuk memaksimalkan penyebaran pesan mereka. Tujuan mereka adalah untuk mendapatkan pendukung dan bisa mempengaruhi suatu stakeholder.

Soebiraj (2020:9) menjelaskan bahwa sebenarnya media sosial memiliki potensi yang sangat besar bagi para politisi untuk berbicara langsung kepada masyarakat. Beberapa anggota masyarakat mempunyai keinginan agar para politisi bersikap transparan dan menanggapi secara jujur aspirasi masyarakat walau pernyataannya cukup pedas. Adanya umpan balik yang diberikan oleh publik terhadap media sosial organisasi politik/politisi walaupun pesannya bersifat kritis adalah adanya nilai demokrasi. Dengan kemudahan yang diberikan, para politisi atau organisasi politik sering kali menerima pelecehan dan permusuhan di media sosial.

Dilihat dari perspektif teori difusi inovasi, strategi yang digunakan oleh akun twitter Partai Gerindra memiliki maksud untuk lebih dekat dan berbaur dengan masyarakat, namun selain itu tujuan dari Hal tersebut terkait dengan pernyataan Joseph (2012:33) yang menjelaskan bahwa media sosial dapat menjangkau berbagai kalangan termasuk para pemilih muda untuk berpartisipasi lebih besar (Joseph, 2012:33).

Pada akhirnya kita melihat bahwa media sosial telah memungkinkan serangkaian keterjangkauan teknologi yang akan berguna sejauh mana mereka dapat dipisahkan dari bisnis rakus di ruang publik. Namun kekhawatirannya adalah media sosial lebih memungkinkan para penguasa untuk menghindari segala pertanyaan kritis dari masyarakat. 


\section{KESIMPULAN}

Hadirnya media sosial yang digunakan sebagai platform untuk melakukan pertukaran informasi sangat dimanfaatkan oleh politisi untuk melaksanakan komunikasi politik. Tidak heran jika organisasi politik menggunakan media sosial untuk mempengaruhi sikap masyarakat terhadap citra mereka, mempunyai agenda serta maksud tertentu bahkan melakukan kampanye secara terselubung. Berikut beberapa poin dari kajian literatur yang didapatkan oleh peneliti:

1. Twitter adalah media sosial yang efektif untuk melakukan komunikasi politik terhadap generasi muda.

2. Twitter sebagai media sosial merupakan aset masa kini dan masa depan bagi para politisi dan organisasi partai karena dapat menjangkau calon pemilih di masa depan melalu komunikasi di masa kini.

3. Twitter sebagai media sosial akan memberikan lebih banyak pengaruh yang signifikan dengan diadakannya komunikasi politik yang disampaikan melalui tweet.

4. Penerapan Teori Difusi Informasi pada partai gerindra terlihat ketika adanya penggunaan media twitter sebagai platform komunikasi partai dengan para audiensnya. Selain itu partai gerindra mengubah gaya komunikasi mereka dengan gaya yang lebih santai agar bisa terkait dengan generasi muda yang menggunakan twitter.

\section{DAFTAR PUSTAKA}

Abdillah, Leon A. (2020). Social Media as Political Party Campaign in Indonesia. Jurnal Ilmiah MATRIK Vol.16 No.1, April 2014:1 -10.

Arifin, Anwar. (2011). Komunikasi Politik (Filsafat - Paradigma - Teori - Tujuan - Strategi dan Komunikasi Politik Indonesia. Yogyakarta: Graha Ilmu.

Chang, Hsia-Ching, (2010). A new perspective on Twitter Hashtag Use: Diffusion Inovation Theory. Chang, H.-C. (2010). A new perspective on Twitter hashtag use: Diffusion of innovation theory. Proceedings of the American Society for Information Science and Technology, 47(1), 1-4. doi:10.1002/meet.14504701295

Creswell, J. (2009). Research design: Qualitative, quantitative, and mixed methods approaches.

California: SAGE Publications, Inc.

Crawford, K. (2009). Following you: Disciplines of listening in social media. Continuum: Journal of Media \& Cultural Studies, 23(4), 525-535.

Daymond, Christine \& Holloway, Immy (2008). Metode Riset Kualitatif. 2nd ed. Jogjakarta: Press Media. 131.

Dearing, James W. Cox, Jeffrey G. (2018). Diffusion of Innovations Theory, Principles and Practice. 10.1377/hlthaff.2017.1104. HEALTH AFFAIRS 37,NO. 2 (2018): 183-190.

Grishin, S.E. (2012). Political Communications. Saratov. Slovo Publishing House

Hanley, Terry., Cutts, Laura. (2013). What is systematic review?. The British Psychological Society-ISSN.0269-6975.

https://www.researchgate.net/publication/259592128_What_is_a_systematic_review

Joseph, S. (2012). Social Media, Political Change, and Human Rights. Boston College International \& Comparative Law Review, 35(1).

Krippendorf, K. (2004). Content Analysis: an Introduction to Its Methodology. SAGE Publications. London.

Laughey, Dan. (2007). Key Themes in Media Theory. Open University Press. 
Leonardo, Paul M. Huysman, Marleen. (2012). Enterprise Social Media: Definition, history and prospect for the study of social technologies in organizations. Journal of Computer Mediated Communication. 19(1), 1-19. doi:10.1111/jcc4.12029.

Manning, J. (2014). Social Media, definition and classes of. Sage. Page. 1158-1162.

Ma, L., Sian Lee, C., \& Hoe-Lian Goh, D. (2014). Understanding news sharing in social media. Online Information Review, 38(5), 598-615. doi:10.1108/oir-10-2013-0239

Mulyadi, Agus. Dari Admin Twitter Gerindra Kita Belajar Bahwa Satu Twit Bisa Merusak Branding yang Sudah Dibangun Lama. 27 Mei 2021. https://mojok.co/agm/pojokan/dariadmin-twitter-gerindra-kita-belajar-bahwa-satu-twit-bisa-merusak-branding-yang-sudahdibangun-lama/.

Sobieraj, Sarah. Masullo, Gina M. dkk. (2020). Politicians, Social Media, and Digital Publics: Old Rights, New Terrain. Sagepub. DOI: 10.1177/0002764220945357. 